\title{
Garducci y Gutiérrez Nájera: dos ejemplos de lectura de Horacio en la tradición clásica del siglo XIX
}

\section{Carducci and Gutiérrez Nájera: Two Examples of Reading of Horace in the Glassical Tradition of xIx Century}

\author{
Néstor Elián Manríquez Lozano \\ Universidad Nacional Autónoma de México \\ Facultad de Filosofia y Letras, México \\ nestormalo@gmail.com
}

\section{RESUMEN}

Manuel Gutiérrez Nájera y Giosuè Carducci son dos de los más destacados autores de México e Italia respectivamente. Ambos, inspirados por la poesía francesa de su tiempo, tuvieron un ideal literario que incluía la búsqueda de una definición y una construcción de la identidad nacional. Entre los distintos medios para llevar a cabo esta tarea, el uso de la tradición clásica, y en específico de la presencia de Horacio, nos permite apreciar las diferencias y similitudes de las corrientes ideológicas decimonónicas en las que ambos se encontraban.

\section{Palabras clave}

Modernismo, Manuel Gutiérrez Nájera, Giosuè Carducci, risorgimento, poeta nacional, tradición clásica, Horacio.

\section{ABSTRACT}

Manuel Gutiérrez Nájera and Giosuè Carducci are two of the most important authors of Mexico and Italy respectively. Both were inspired by the French poetry of their time and shared a literary ideal of definition and construction of their national identity. Among the different ways to do this work, the use of Classical tradition, and specifically in the presence of Horace, allows us to recognize the differences and similarities of the nineteenth-century ideas of both authors.

\section{KEYWORDS}

Modernism, Manuel Gutiérrez Nájera, Giosuè Carducci, risorgimento, National poet, Classical tradition, Horace.

RECEPCIÓN: 03/09/2020

ACEPTACIÓN: 14/10/2020 


\section{Gutiérrez Nájera y Carducci: desconocidos contemporáneos}

El lugar que ocupa un autor dentro de la historia literaria de un país normalmente se mide no sólo por su obra, sino también por el eco que ésta tiene en las generaciones posteriores. Manuel Gutiérrez Nájera, el llamado Duque Job, hombre considerado iniciador del modernismo mexicano junto a preeminentes miembros de las letras mexicanas, como Carlos Díaz Dufoo y Luis G. Urbina, y que, según José Emilio Pacheco, "fue el primer escritor profesional de México" (Pacheco, 2019: 60), sentó las bases de la literatura mexicana para distintos géneros que se consolidarían en el siglo $\mathrm{xx}$, desde la investigación periodística hasta la creación poética, y fue inspiración posterior para escritores tan destacados como Rubén Darío u Octavio Paz.

De forma similar, el autor toscano Giosuè Carducci, "Il poeta vate d'Italia", comúnmente identificado con la región emilo-romañola y, en específico, con la ciudad de Bolonia, donde hasta la fecha se conserva su casa - ahora convertida en un museo-, fue el primer italiano en ganar el Premio Nobel de Literatura y principal representante de la poesía de la Terza Italia, que constituía, como dice Luigi Russo, "la reacción al vago poeticismo romántico" (Russo, 1955: 243); ${ }^{1}$ además, en su quehacer poético tuvo la meta de formar una cultura italiana que recuperara su más recóndito pasado romano (véase Russo, 1955: 243).

Ambos autores, que fueron prácticamente contemporáneos, ${ }^{2}$ desarrollaron su trabajo a finales del siglo XIX en entornos geográficos y bajo preceptos de creación literaria y posturas notoriamente distintos sobre la apreciación o desprecio de la influencia extranjera en su obra. No obstante, en puntos destacados, confluyeron en ideas y en una preocupación por la construcción de una identidad nacional análoga.

Con base en lo anterior, el presente trabajo relacionará la obra de Carducci y de Gutiérrez Nájera a través de la tradición clásica existente en ella, ${ }^{3}$ en particular, mediante el análisis de las evocaciones que éstos hacen del poeta latino Quinto Horacio Flaco para mostrar la forma en que las fuentes clásicas operan en dos países y tradiciones literarias diferentes que se encontraban en un paralelo cronológico. La pertinencia de una comparación entre dichos autores radica no en asumir que la tradición clásica funciona de una manera similar en la obra de ambos o que sea equiparable la presencia

${ }^{1}$ Todas las traducciones de textos en otras lenguas son mías.

${ }^{2}$ Aunque Carducci fue mucho más longevo (1835-1907), Gutiérrez Nájera (1859-1895) fue más prolífico que el poeta italiano, quien, aunque comenzó a escribir a temprana edad, también siguió desarrollando su obra hasta muy cercana la fecha de su muerte.

${ }^{3}$ Si bien la definición del concepto de "tradición clásica" siempre es controversial y compleja, considero que podemos tomarlo como la simple presencia, implícita o explícita, consciente o inconsciente, de elementos clásicos en un autor posterior. Un buen acercamiento a este tema se encuentra en Aparicio (2013). 


\section{Carducci y Gutiérrez Nájera: dos ejemplos de lectura de Horacio}

de Horacio en ellas con una motivación literaria compartida, sino en observar los distintos mecanismos poéticos que pueden utilizar autores del mismo tiempo para emplear la presencia de obras grecolatinas en su obra, de modo que sirva para complementar nuestro conocimiento tanto sobre los escritores de llegada, Carducci y Gutiérrez Nájera en este caso, como sobre los textos de partida. La intención tampoco será profundizar en la obra general de ambos autores, sino ejercitar, a través del contraste, la búsqueda de diferencias, y no necesariamente concordancias, que ayuden a definir una postura sobre la función de la tradición clásica a finales del siglo xIX y principios del XX.

En el caso de Carducci, hay muchos estudios que refieren la evidente presencia horaciana en la construcción de toda su obra. En lo que atañe a Gutiérrez Nájera, la elección de un verso horaciano como título de un poema najeriano será el conductor de la investigación para observar la manera en la que tanto la tradición como la recepción clásicas funcionan a partir de una mención textual. El objetivo de contrastar dos escritores cronológicamente comunes - a pesar de tener, como ya se dijo, una amplia bibliografía sobre el tema en el caso del italiano y una escasa en el del mexicano - será demostrar que la tradición clásica puede funcionar de formas diferentes, incluso cuando se utiliza el mismo autor, y que la presencia o la ausencia de éste en determinada obra no debe condicionarse a si sólo se hace una mención textual o si se propone una imitación literaria.

\section{Horacio en Giosuè Carducci}

En Carducci, según se refirió antes, la influencia de Horacio fue más que evidente; además de escribir piezas con títulos homónimos a las del poeta latino, como los Giambi ed Epodi o sus Odi Barbare, de acuerdo con Elizabeth Hazelton, ambos autores tuvieron vidas con similitudes obvias: los dos partieron de un pequeño pueblo campestre hacia la ciudad cosmopolita de Roma para recibir educación. La recurrente presencia horaciana en la obra carducciana se nota desde los metros que utilizó en sus poemas hasta las constantes referencias intertextuales a los temas que el poeta latino expone a lo largo de toda su producción literaria (Hazelton, 1949: 387-389).

Su sobrenombre también resulta por demás sugestivo. La palabra vate, como un concepto híbrido - sinónimo de poeta y guía del pueblo-, es de total manufactura horaciana (véase Tarrant, 2012). Asimismo, en su muy amplio catálogo poético hay abundantes alusiones directas a Horacio. La primera la encontramos en la epístola introductoria a su colección inaugural de poemas, fuvenilia, donde en el verso inicial menciona el nombre del poeta a manera de dedicatoria: "Ah per te Orazio prèdica al vento del patrio carcere non sei contento" (Carducci, 1999, v. 1: 3). ${ }^{4}$

4 "Ah, para ti, Horacio, la plegaria al viento que de la patria cárcel no estás contento". Esta mención a Horacio no sólo es nominal, hay una alusión en el desarrollo posterior del poema 
Es muy importante destacar que la aparición de Horacio desde las primeras obras poéticas de Carducci no es fortuita. Éste, como su heredero, conocía perfectamente la relevancia y definición que marcaba el poema o, en este caso, carta introductoria de una colección poética. El autor italiano parece sugerirnos que Horacio representará un medio necesario de acceso a su obra y que su desconocimiento condenará al ostracismo de comprensión de su poesía a todo aquel que intente acercarse a ella. Esto se confirma continuamente en su obra. La presencia del poeta romano está marcada, también, por la adopción de los metros horacianos y su conversión a los modos italianos; parafraseando el propio verso de Horacio que cierra el tercer libro de Carmina, donde afirmaba ser el primero en trasladar los versos griegos a modos itálicos: "ex humili potens princeps Aeolium carmen ad Italos deduxisse modos" (Horacio, Carmina, III, 30: vv. 13-14). ${ }^{5}$

La posición de Carducci frente a los movimientos poéticos de su tiempo encontró una perfecta vía de expresión a través de muchas de las ideas que rescataba de Horacio. La apropiación métrica fue sólo un camino en el proceso de afiliación y recuperación que buscaba establecer entre el italiano y su madre, el latín. ${ }^{6}$ Los temas y autores que influyeron en Horacio también lo hicieron en Carducci, y la conversión, traducción o cita de frases latinas de diferentes autores estuvieron constantemente presentes en toda la obra del vate de Italia. Benedetto Croce afirmaba que en la obra carducciana podían encontrarse seis periodos distintos que no estaban marcados de forma cronológica, sino temática: literario, práctico, autobiográfico, político-ético, histórico-épico y, finalmente, erudito; cada uno de éstos - dependiendo de la época de su vida en la que los exploró - mostraba la tendencia política y la visión social del poeta, que fueron en extremo cambiantes, en consonancia con el momento histórico al que perteneció (véase Croce, 1907). No obstante, la presencia del poeta de Venosa es uno de los puntos que jamás desapareció de su obra y que sirvió para demostrar la postura crítica que lo acompañó a lo largo de su vida.

Al igual que en Juvenilia, Carducci elabora en el Prólogo de una de sus colecciones poéticas más importantes, las Odi Barbare, una alusión directa a un poema de Horacio que desarrollará de forma particular. El primer verso es un intertexto de los Carmina

al Ars Poetica (386-390), donde Horacio pedía guardar 9 años cualquier escrito antes de publicarlo. Éste y todos los poemas de Carducci son tomados de la edición de Poesie (1999).

5 "de origen humilde, el primero en convertir el canto eolio a los modos ítalos". Ésta y todas las menciones al texto de Horacio siguen el texto latino de la edición de Friedrich Klingner.

${ }^{6}$ Cabe destacar que, aun cuando parecería que Carducci ejerció un nacionalismo casi xenofóbico, éste congenió con ideas políticas francesas que, como dice Giampiero Carocci, terminaron por convertirse en una influencia cultural y literaria en su obra (Carocci, 1950: 90). Lo anterior es uno de los paralelos que más adelante haremos notar en relación con la formación cultural de Gutiérrez Nájera. 


\section{Carducci y Gutiérrez Nájera: dos ejemplos de lectura de Horacio}

de Horacio: "Odi profanum vulgus et arceo" (Horacio, Carmina, III, 1: v. 1), ${ }^{7}$ que pretende establecer el tono del resto de su colección:

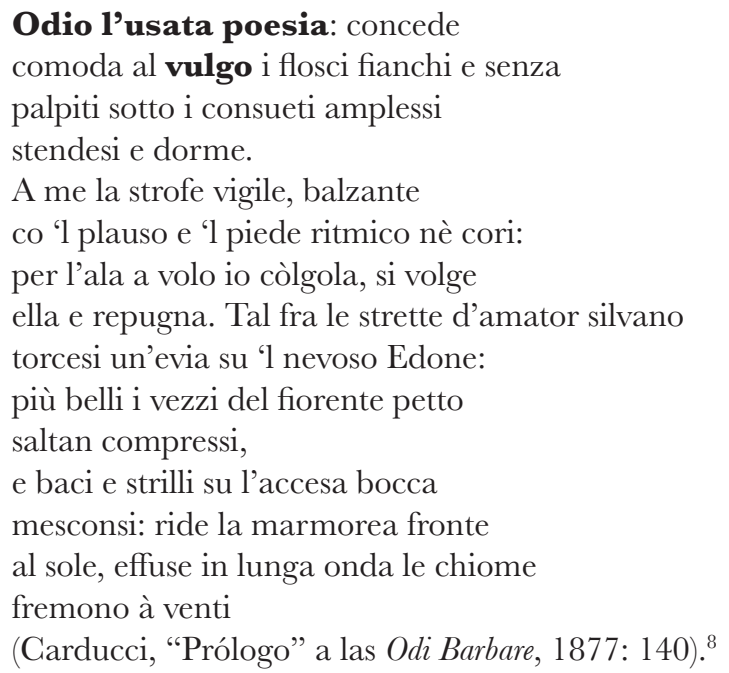

Carducci, desde el comienzo del poema, quiere mostrar la relación que hay entre la poesía y el acto sexual. Palabras como flosci fianchi, palpiti, consueti amplessi y stendesi nos transmiten la idea de que la poesía corriente es como una mujer que se otorga fácil y que está acostumbrada a que cualquiera que se acerque pueda tener acceso a ella. Para ejemplificar el acto, Carducci recurre a una imagen horaciana en el verso en donde menciona a una bacante, utilizando la palabra Evia, término nada común en la lengua latina y mucho menos en la lengua italiana, que nos remite a un pasaje de otra oda horaciana. ${ }^{9} \mathrm{El}$ rechazo de una bacante o quizás una ninfa a los intentos de ultraje de un sátiro en un escenario nevado, donde, después de un gran esfuerzo, el amante tal vez logre, finalmente, su cometido, no sin antes enfrentarse a una fuerte resistencia,

7 "Odio al vulgo profano y me alejo".

8 "Odio la poesía corriente: concede/ cómoda al vulgo los flojos flancos y, sin/ perturbación, bajo acostumbrados abrazos, / se tiende y duerme./ Para mí es la estrofa viva, que salta/ con el aplauso y el pie rítmico en los coros:/ yo la atrapo por el ala al vuelo, se retuerce/ ella y me rechaza. Tal como entre los apretones del amante del bosque/ se retuerce una evia sobre el nevado Edón:/ más bellos los collares del florido pecho,/ saltan comprimidos, / y besos y gritos sobre la boca/ encendida se mezclan: ríe la frente marmórea/ al sol, esparcidas en larga ola las cabelleras/ braman a los vientos".

9 "Non secus in iugis/ exsomnis stupet Euhias,/ Hebrum prospiciens et niue candidam/ Thracen ac pede barbaro/ lustratam Rhodopen" (Horacio, Carmina, III, 25: vv. 8-12) [“Como la Evia insomne observa en las cumbres el Hebro y con nieve la cándida Tracia y la Ródope lustrada con el pie bárbaro"]. 
denota que, en el ideal carducciano, el acercamiento a la poesía que no es corriente y de fácil acceso al público, es decir, a la que aspira un autor como él, siempre será algo difícil y que, para valer, requerirá de un gran esfuerzo de por medio, no como la primera que menciona en el poema que se otorga con facilidad a cualquier lector.

Resulta interesante que el texto de Horacio, en el cual se inspira Carducci para hacer este desarrollo, muestra una total ausencia del elemento sexual que en el poema del italiano constituye la metáfora principal. Horacio sólo refiere, al comienzo de su poema, que expondrá poemas que no han sido escuchados antes, y utiliza un lenguaje que ubica su trabajo dentro del contexto religioso y ritual más que en el amoroso y vulgar. Horacio afirma que su poesía es sacra y no profana, sus palabras son las de un sacerdote de las Musas que mostrará algo nuevo que ningún hombre o mujer romanos - y la aparición del término virgines confirma el contexto sacro- ha conocido. Parecería que el contexto textual en el que Carducci desarrolla este motto inicial ${ }^{10}$ tomado de Horacio simplemente es una innovación propia. El poeta italiano en realidad está recuperando el tono y el tema del propio poema que Horacio utilizó para mostrar un

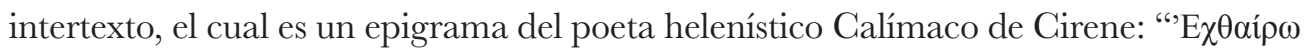

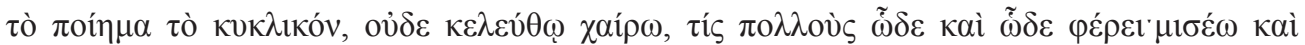

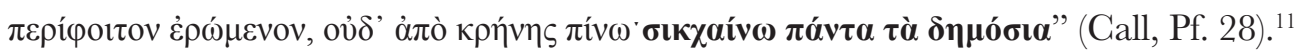

Es bien sabido que la frase "Odi profanum vulgus" aparece en la oda horaciana como un intertexto calimaqueo que no está al comienzo del epigrama del poeta griego. Horacio extrajo dicha expresión y la usó como un elemento conductor de la temática de su poema de la misma forma que lo hizo con el desarrollo de cualquier motto intertextual en su obra.

En el epigrama, Calímaco formula primero su odio por el poema épico, asunto que amerita y que ha tenido ya un tratamiento amplio en muchos otros estudios, ${ }^{12}$ para posteriormente criticar el camino que lleva a uno u otro lugar, pero, en especial

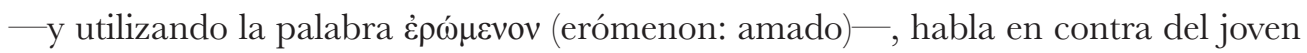

${ }^{10} \mathrm{El}$ motto inicial es una técnica en la que el autor toma el primer verso de un poema o estrofa del de algún otro escritor para desarrollar una nueva obra poética a partir de él. Lo reconoce Pasquali en el Orazio lirico al describir la relación entre Horacio y Alceo (Citroni, 2011: 571). La importancia del concepto de motto es fundamental en la transición hacia el arte allusiva de Pasquali, como afirma Citroni: "The motto formula happily expresses the idea of an open statement of ideal filiation from an artistic or intellectual point of reference, without any prejudice against the autonomy of the poet's own discourse" (Citroni, 2011: 572) ["El motto expresa felizmente la idea de una afirmación abierta de filiación ideológica desde un punto artístico o intelectual de referencia, sin ningún prejuicio en contra de la autonomía del propio discurso del poeta"].

11 "Odio el poema cíclico, ningún camino me gusta que arrastra a muchos aquí y allá; detesto al amante vagabundo, de la fuente pública no bebo: desprecio todo lo popular".

12 Véase Acosta-Hughes, Lehnus y Stephens (2011). 


\section{Carducci y Gutiérrez Nájera: dos ejemplos de lectura de Horacio}

amante que va por todos lados sugiriendo su promiscuidad, y afirma que no bebe de la крฑ́vๆ (kréne), es decir, de la fuente pública. Este pasaje, que se ha leído a partir de la contraposición de la natural pureza y claridad del agua frente a aquella que, al surgir de una fuente pública y, por lo tanto, ofrecerse a cualquier contaminación vulgar o cotidiana, no puede probarse por completo ya su pureza, nos da indicios

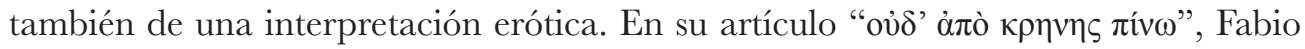

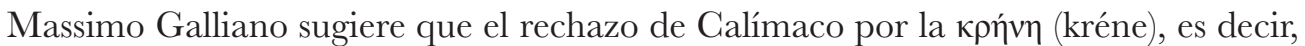
la fuente pública, que representa, a su vez, un intertexto probablemente tomado de una síloge teognidea, ${ }^{13}$ se debe a la contraposición hecha entre la fuente natural y la fuente artificial de ciudad; ese rechazo, al mismo tiempo, puede insinuar la relación entre las fuentes y los ríos con las ninfas, quienes encarnaban estos lugares y que, al volverse citadinas, perdían también su pureza y se convertían en otro tipo de mujeres (Galliano, 1997: 155-157).

Aunque sea improbable que esta conexión textual haya sido percibida de esa forma por Carducci, sí puede afirmarse que el poeta conduce el intertexto horaciano hacia un camino erótico que está mucho más presente en el arquitexto calimaqueo. ${ }^{14}$ El poeta italiano no rechaza lo citadino, sino lo ignorante, y ofrece pruebas de ello en sus menciones mitológicas elaboradas y en sus relaciones textuales horacianas que enriquecen su texto, al mismo tiempo que lo complican. Es obvio que esto nos dice mucho más que nociones poéticas. Carducci intentó construir, tal como él lo apreciaba en Horacio, una obra que fuera representación de la nación que quería formar y a la que deseaba pertenecer. Como las "Odas romanas" de Horacio, ${ }^{15}$ Giosuè Carducci busca hacer odas nacionales que puedan servir de base para la conformación del proyecto de la Nueva Italia. Para ello, pide que el lector haga un esfuerzo y que no piense que todo será accesible y fácil para aquellos que se interesen en colaborar en dicho proyecto. La mentalidad de Carducci como teórico iba siempre por el camino del rechazo más que por la propuesta para construir su ideal de nación, sabiendo qué debía ignorarse o ponerse a un lado en la conformación de una nación italiana. Profesaba el anticristianismo en la religión, antimonarquismo en la política y antirromanticismo en la literatura. Es probable que los ideales clasicistas de él y de sus "amigos pedantes"

\footnotetext{
${ }^{13}$ Una colección de textos atribuidos comúnmente al poeta griego arcaico Teognis de Megara.

${ }^{14}$ Consideramos que, en la cadena de tradición del texto carducciano, el epigrama de Calímaco, al ser el primer elemento poético que hace uso de la fórmula de desprecio a lo común, sería el arquitexto que, de una u otra forma, puede seguir dejando huella en las constantes reelaboraciones surgidas del poema horaciano.

${ }^{15}$ Son conocidas como "Odas romanas" las 6 primeras odas del libro III de Carmina de Horacio. Éstas, además de tener una relación métrica, establecen un programa poético que normalmente se cree que fue encargado por el emperador Augusto como modelo de comportamiento para la sociedad romana de su tiempo.
} 
- apodo con el que su grupo se autonombraba con orgullo - y su férrea oposición al romanticismo - Carducci pensaba que la poesía romántica era poesía corriente que otorgaba con facilidad su cuerpo y no cumplía con la mayor obligación de un poeta que era educar al pueblo - provocaran que, en tiempos modernos, su obra no sea tan estudiada o recordada como debería.

\section{Horacio en Manuel Gutiérrez Nájera}

Un contemporáneo de Carducci, que nació y vivió a más de un océano de distancia y que disfrutó menos de la mitad de los años que él, fue el mexicano Manuel Gutiérrez Nájera. Constantemente presente para la crítica, pero olvidado por el lector actual, realizó una lectura de Horacio con observaciones e intenciones muy distintas a las que mostró el Scudiero dei classici. ${ }^{16}$ Gutiérrez Nájera no encontró en la poesía su género más destacado - lo cual podría confirmarse por el volumen de su obra y la dispersión de la misma-, sino en la crónica y la crítica, que, no obstante, siempre dieron muestras del oficio poético del autor.

Como iniciador del modernismo en México, Gutiérrez Nájera tuvo características muy especiales en su carácter de autor y de crítico que, en algunos casos, pueden verse en paralelo con Horacio. Niall Rudd afirma que uno de los rasgos que hizo de Horacio un poeta moderno fue su capacidad de haber creado su propia audiencia (Rudd, 1989: 4). Gutiérrez Nájera, además de haber realizado esto, como el gran modernista mexicano, se ocupó conscientemente de crear una literatura nacional propia.

Así pues, uno de los primeros puntos notables que podemos comparar entre Gutiérrez Nájera y Carducci a través de Horacio es su interpretación del concepto del profanum vulgus (que ya analizamos y desarrollamos ampliamente en la obra del italiano). No en un poema, sino en un artículo que dedica como respuesta a críticas hechas a su magnum opus, la serie de poemas que conforman Tristissima Nox, Gutiérrez Nájera dice lo siguiente: "[El móvil de estos versos] debió ser cierto deseo que usted comprenderá porque es artista, pero que es inexplicable para el vulgum pecus: presentar un estudio de claroscuro [...] oponerle luz a la sombra, el negro intenso al blanco deslumbrante"(Gutiérrez Nájera en Puga, 1888: 115).

Es obvio que el término najeriano no está tomado ad litteram de la oda horaciana. En realidad, el Duque Job hace un cruce entre ese concepto y otro que aparece también en el mismo Horacio en la epístola donde exclama: "O imitatores, servum pecus!" (Hor. Epist. 1.19.19). Este término no refiere, como en el caso de Carducci, a la poesía que es accesible a todos, sino a la imposibilidad de llevar a cabo una crítica profunda sobre el quehacer del poeta por alguien que no lo es. El artista, sin importar

\footnotetext{
${ }^{16}$ Sobrenombre con el que se identifica a Carducci entre el resto de sus amici pedanti.
} 


\section{Carducci y Gutiérrez Nájera: dos ejemplos de lectura de Horacio}

su nombre o capacidad, no es parte de ese servum pecus ${ }^{17}$ porque conoce su trabajo y sabe las implicaciones que éste tiene.

Es natural ver que el odio horaciano tuvo distintas interpretaciones y usos que dependieron de los intereses de cada autor. Miguel de Unamuno, por ejemplo, escribe: "Odi profanum vulgus, dijo una vez Horacio y yo aborrezco, más que al vulgo profano, a los conventículos y cotorrillos de literatos" (Unamuno, 1950: 937). Sin embargo, el cambio que produce Manuel Gutiérrez Nájera intencionalmente en la frase nos sugiere que los ideales horacianos necesitaban una adaptación a las ideas que el escritor mexicano quería reflejar, una adaptación del concepto o apropiación que puso en práctica también en otro momento con un elemento horaciano.

El poema "Non omnis moriar" tiene por título el comienzo del sexto verso del último poema del libro III de Carmina de Horacio: "non omnis moriar, multaque pars mei/ vitabit Libitinam" (Horacio, III, 30: vv. 6-7)..$^{18}$ El texto del Duque Job es el siguiente:

¡No moriré del todo, amiga mía!
de mi ondulante espíritu disperso,
algo en la urna diáfana del verso,
piadosa guardará la poesía.

¡No moriré del todo! Cuando herido

caiga a los golpes del dolor humano, ligera tú, del campo entenebrido

levantarás al moribundo hermano.

$¡$ ¡Tal vez para entonces por la boca inerme que muda aspira la infinita calma, oigas la voz de todo lo que duerme con los ojos abiertos de mi alma!

Hondos recuerdos de fugaces días, ternezas tristes que suspiran solas; pálidas, enfermizas alegrías sollozando al compás de las violas...

Todo lo que medroso oculta el hombre se escapará vibrante del poeta, en áureo ritmo de oración secreta que invoque en cada cláusula tu nombre.

${ }^{17}$ Este concepto najeriano tuvo una rápida difusión. Pasó por las palabras de Andrés Bello al decir "servum pecus de los imitadores de la literatura", hasta llegar a Octavio Paz, quien lo utilizó en por lo menos una ocasión.

18 "no moriré del todo, gran parte de mí/ evitará a Libitina". 
Y acaso adviertas que de modo extraño suenan mis versos en tu oído atento, y en el cristal, que con mi soplo empaño, mires aparecer mi pensamiento.

$\mathrm{Al}$ ver entonces lo que yo soñaba, dirás de mi errabunda poesía: era triste, vulgar lo que cantaba...

mas, ¡qué canción tan bella la que oía!

Y porque alzo en tu recuerdo notas del coro universal, vívido y almo; y porque brillan lágrimas ignotas en el amargo cáliz de mi salmo;

porque existe la Santa Poesía y en ella irradias tú, mientras disperso átomo de mi ser esconda el verso, ¡no moriré del todo, amiga mía!! ${ }^{19}$

Al iniciar el poema, Gutiérrez Nájera sugiere que no intentará una recreación exacta del poema y que, al no imitarlo palabra por palabra, no se centrará en reproducir cada concepto horaciano, sino en un elemento particular, como en Carducci, es decir, el desarrollo a partir de un motto: la imitación como eje de la creación poética para poder construir una idea propia. El poeta latino dice que una parte de él sobrevivirá en su poesía y que su nombre continuará creciendo mientras siga siendo leído y Roma siga en pie. El Duque Job comienza su poema retomando esta idea: la poesía será como una urna donde algo de su espíritu se conservará. No obstante, en la segunda estrofa, Gutiérrez Nájera empieza a tomar un camino diferente.

La idea de la pervivencia de su poesía no va dirigida a la imprecación a una musa, como en el caso de Horacio, sino a una amiga suya a quien destina el poema y a quien confía la pervivencia de su alma en forma de verso. Gutiérrez Nájera pretende construir una literatura mexicana no a través de su figura de líder de ideales o como vate carducciano que guíe y sirva como profeta anunciando la divinidad al pueblo, sino por lo que su propia poesía despierta en el lector. El ideal de trascendencia del poeta habla cuando el hombre calla y se mantiene a través del recuerdo que su amada tiene de él, marca un tono muy distinto al abordado por Carducci y al que Horacio registra en su obra, atribuible, probablemente, a la línea teórica e ideológica modernista en la que se encontraba Gutiérrez Nájera, y la cual, al mismo tiempo, estaba definiendo.

${ }^{19}$ Poema publicado en El Diario del Hogar (vol. XIII, núm. 214, 27 de mayo de 1894b, p. 1) y en la Revista Azul (t. 1, núm. 1, 6 de mayo de 1894a, p. 8). 


\section{Carducci y Gutiérrez Nájera: dos ejemplos de lectura de Horacio}

El modernismo tiene la particularidad de utilizar cualquier recurso o tendencia literaria que le plazca sin discriminación mayor que el gusto personal del poeta que hace uso de su pluma. Ésta fue una de las razones por las que dicho movimiento gozó de tantas posturas literarias tan diferentes como cada uno de los miembros que lo integraron, las cuales no se veían agrupadas o constreñidas por líneas específicas, pues había una plena expresión del individualismo del escritor, "un sentimiento de optimismo y posibilidad”, como refiere Aníbal González (González, 2007: 3).

Gutiérrez Nájera, al igual que muchos de sus contemporáneos, siempre tuvo preferencia y un gusto especial por la poesía francesa parnasiana y simbolista. Juan Pascual Gay dice: "con Nájera, la literatura vuelve sus ojos a Francia como espacio de inspiración, como referencia obligada, como paradigma de una sensibilidad" (Gay, 2014: 17). Del mismo modo que el clasicismo de Carducci lo hizo ver ante la gente común como un pedante, el afrancesamiento del Duque Job y de sus contemporáneos los mostró ante algunos sectores de la opinión pública como presas de un amaneramiento que rayaba en la sensiblería.

Podemos saber mucho sobre la postura poética de Gutiérrez Nájera mediante su crítica y sus crónicas, donde mostraba las ideas que tejían los versos que éste creó en su obra poética. El amplio rango de creación literaria cultivado le granjeó no sólo el nombre de escritor, sino también de intelectual (Clark, 2019: 27). El poeta mexicano veía en la belleza un bien supremo que era más o menos próximo, pero que nunca lograba ser totalmente accesible al artista. En su artículo "El arte y el materialismo" (1876), el autor señalaba que "nosotros no comprendemos lo bello absoluto, ni podemos siquiera concebirlo, porque esa revelación es demasiado grandiosa para la mezquina inteligencia del hombre" (Gutiérrez Nájera, 2016: parte III). Un modo necesario de aproximación a la trascendencia es la belleza, y ésta, aunque inaccesible, resulta el bien que debe buscarse en la práctica del artista.

Si seguimos esta idea, Gutiérrez Nájera concibe la Santa Poesía, que menciona hacia el final de su poema, como un sinónimo de la Belleza. El encuentro de la amante y del poeta es la poesía, porque en ella está la belleza, y mientras al poeta le es inaccesible de forma completa por sí mismo, en la unión con la amante provoca un punto de encuentro que tiende hacia la inmortalidad.

Dicha visión del mundo está totalmente alejada de cualquier principio poético horaciano y del clasicismo recalcitrante carducciano, la interpretación sexual de la poesía como un personaje femenino que debe poseerse no se presenta en lo absoluto en el poema del Duque Job. Él considera que la imitación de los clásicos, por el desconocimiento propio de su época, está perdida en un mar de modas, como sucede en la literatura española, en la que percibe sólo poesía insípida y descolorida que no es ni antigua ni moderna. Aun cuando no afirma que la poesía española imita banalmente modelos extranjeros, sí sugiere que deben conocerse en profundidad, porque la raíz 
de la poesía se encuentra, justo, en el conocimiento, y éste es la vía de acceso del poeta a construir a través del culto a lo bello. El escritor mexicano entiende que esa belleza llega mediante un proyecto, en el que la estética ocupa el lugar más importante, aunque, de la misma forma, su "labor política revólver", como la ha llamado Belem Clark en distintas ocasiones, sirvió para ayudar a construir o destruir a destacados personajes políticos.

\section{Encuentros y desencuentros}

La forma de expresión poética del modernismo nos muestra las ideas tan contrastantes de los autores mexicanos de esta corriente con respecto a los europeos. Las colecciones poéticas o la publicación de manifiestos no fueron el vehículo idóneo de divulgación de esas ideas, sino las revistas, entre las cuales destaca, sin lugar a dudas, Revista Azul. La postura del intelectual modernista y sus constantes contradicciones hacen de ellas el medio perfecto de expresión. Dentro de las revistas, un artículo de opinión o un ensayo no necesariamente comulga ideológicamente entre sí con todo el contenido que se expone en ellas, la pluralidad es una constante y la reconstrucción de una postura ideológica necesariamente debe tomar en cuenta el contexto cronológico del autor. Esto, obviamente, también marca un contraste con respecto a la ideología del poeta nacional que representa Carducci.

La posición de los poemas de influencia horaciana al comienzo de las obras del autor italiano es una herencia de criterios editoriales que utilizó el escritor latino, que muestra la construcción de un proyecto de poesía a manera de obra completa, donde cada colección tiene un lugar importante en la consolidación de su camino como vate de Italia. Al contrario, Gutiérrez Nájera liga la difusión de su poesía, en la mayoría de las ocasiones, al soporte periodístico, como un objeto que no forma parte de una colección, por lo que los poemas pueden ser reutilizados y adaptados para publicarse de nuevo en otro lugar.

La idea del intelectual modernista será que a la creación se llega mediante la inclusión, es decir, la mezcla entre la tradición y la modernidad, con una añoranza y una constante búsqueda de la belleza. ${ }^{20}$ Fundar una literatura propia mexicana no puede empatarse con la intención de renovación italiana de una nación compartida por los amici pedanti, donde el clasicismo será muestra no de búsqueda de un ideal de belleza como con Gutiérrez Nájera, sino de alta literatura encarnada tanto por Carducci como por los poetas más importantes de su tiempo, de la talla de Gabriele D’Annunzio y Giovanni Pascoli, cuya intención poética buscaba también un intento de definición nacional.

${ }^{20}$ Este concepto fue compartido en pláticas con la doctora Belem Clark. 


\section{Carducci y Gutiérrez Nájera: dos ejemplos de lectura de Horacio}

Urbina y Díaz Dufoo pretendían, junto a Gutiérrez Nájera, generar algo nuevo, característica de esa generación, como la califica Belem Clark, "sana, fresca, joven y valiente" (Clark, 2000: 49), y no reconstruir algo caduco con una visión idealizada del pasado que funcionara como un reflejo del contexto cultural del presente. La "Flor de otoño del modernismo mexicano", como Justo Sierra llama a Gutiérrez Nájera en el prólogo de la edición de su obra, nos da una pequeña muestra en "Non omnis moriar" de la necesidad de la búsqueda continua de lo bello en la poesía, sin importar qué tan triste o vulgar se juzgue.

Así, concluimos que la interpretación que hicieron ambos escritores de la obra de Horacio es claro ejemplo de su mentalidad y de la afinidad con las ideas del poeta latino, que sirven como un crisol de dos formas de abordar la obra de un autor clásico, en tanto motivo de creación literaria que permite ampliar y enriquecer nuestra definición de la tradición grecolatina. Mientras Carducci intenta crear un estandarte de renovación nacional por medio de lo antiguo, Gutiérrez Nájera ve en el ideal de inmortalidad horaciano un reflejo de su propio anhelo de pervivencia poética a través de la belleza. La identificación y definición de la postura estética del mexicano permiten ver que la redefinición y apropiación de los ideales de un autor clásico pueden ser, al mismo tiempo, el hilo conductor y las bases de la tradición y presencia del clasicismo en el siglo xix. Así como Horacio buscó con su poesía ayudar a formar el nuevo Imperio en manos de Augusto, la obra de Giosuè Carducci y de Gutiérrez Nájera fue una parte esencial de la creación de la literatura de su país; ambos reformaron y cambiaron las letras de sus respectivas naciones.

\section{Bibliografía}

Acosta-Hughes, Benjamin, Luigi Lehnus y Susan Stephens (editors)

Brill's Companion to Callimachus. Leiden: Brill, 2011.

Aparicio Maydeu, Javier

Continuidad y ruptura. España: Alianza, 2013.

Carducci, Giosuè

Poesie. Italia: Garzanti Editore, 1999.

Caroci, Giampiero

"Influenza francese e tradizione classicistica sulla cultura del Carducci", en Annali della Scuola Normale Superiore di Pisa. Lettere, Storia e Filosofia. Italia: Scuola Normale Superiore, volumen 19, número 1 (1950), 87-96.

Citroni, Mario

"Arte Allusiva: Pasquali and Onward", en B. Acosta-Hughes, L. Lehnus y S. Stephens (editors). Brill's Companion to Callimachus. Leiden: Brill, 2011. 


\section{Cilark de Lara, Belem}

"Ascensión en la visión del mundo de Manuel Gutiérrez Nájera", en Actas XIII Congreso AIH. Madrid: Castalia, 2000, 46-56.

"Filología literaria. De la ecdótica a la hermeneútica. 'Plato del día' de Manuel Gutiérrez Nájera”, en (an)ecdótica, volumen III, número 1 (2019), 9-32.

Croce, Benedetto

La Critica, 1907. Volumen 5. Italia: Laterza, 1907.

Galliano, Fabio Massimo

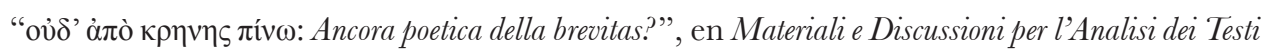
Classici, número 38 (1997), 153-173.

GAY, Juan Pascual

"Cosmopolitismo versus nacionalismo. El intelectual en México 1869-1894", en Mexican Studies/Estudios Mexicanos, volumen 30, número 1 (2014), 1-30.

González, Aníbal

A Companion to Spanish American Modernismo. Woodbridge: Tamesis/Boydell \& Brewer, 2007.

\section{Gutiérrez NÁjera, Manuel}

"Non omnis moriar", en Revista Azul, tomo 1, número 1 (6 de mayo de 1894a), 8.

"Non omnis moriar", en El Diario del Hogar, volumen XIII, número 214 (27 de mayo de 1894b), 1 .

Obras. Estudios y antología general de José Luis Martínez. México: Fondo de Cultura Económica, 2003.

El arte y el materialismo. México: Biblioteca Virtual de México, 2016. Consultado en: https:/ / mexicana.cultura.gob.mx/es/repositorio/detalle?id=_suri:DGB:TransObject:5c95760c7 a8a0230b7329632\#epubcfi [13/06/2020].

Hazelton, Elizabeth

"Giosue Carducci, the Italian Horace", en Studies in Philology. Carolina del Norte: Universidad de Carolina, volumen 46, número 3 (1949), 387-399.

KLINGNER, Friedrich (editor)

Opera: Horatius Flaccus. Berlín: B. G. Teubner, 1959 (Bibliotheca Scriptorum Graecorum et Romanorum Teubneriana).

Pacheco, José Emilio

Antología del modernismo mexicano 1884-1921. México: Era/El Colegio Nacional, 2019.

160 (an)ecdótica vol. V, núm. 2, julio-diciembre 2021 


\section{Carducci y Gutiérrez Nájera: dos ejemplos de lectura de Horacio}

PFEIFFER, Rudolph (editor)

The Fragments of Callimachus. Oxford: Clarendon Press, 1949.

Puga y Acal, Manuel (editor)

Los poetas mexicanos contemporáneos. Ensayos críticos de Brummel. México: Imprenta, Litografía y Encuadernación de I. Paz, 1888.

RuDD, Niall

Horace's Epistles II and Ars Poetica. Cambridge: Cambridge University Press, 1989.

Russo, Luigi

"Carducci senza retorica", en Belfagor. Italia: Casa Editrice Leo S. Olschki s.r.l, volumen 10, número 3 (1955), 241-257.

Schulman, Iván

El proyecto inconcluso. La vigencia del modernismo. México: Siglo XXI, 2002.

Shackleton Bailey, D. R. (editor)

Q. Horati Flacci. Opera. Stuttgart: B. G. Teubner, 1985 (Bibliotheca Scriptorum Graecorum et Romanorum Teubneriana).

TARRANT, Richard

"Lyricus Vates: Musical Settings of Horace's Odes", en Yale Classical Studies. Cambridge: Cambridge University Press, volumen 36 (2012), 72-93.

Unamuno, Miguel de

Obras completas. Tomo IV. Ensayos. Madrid: Afrodisio Aguado, 1950. 